\title{
RESPIRATORY INFECTION
}

\section{Defining community acquired pneumonia severity on presentation to hospital: an international derivation and validation study}

\author{
W S Lim, M M van der Eerden, R Laing, W G Boersma, N Karalus, G I Town, S A Lewis, \\ J T Macfarlane
}

Thorax 2003;58:377-382

See end of article for authors' affiliations

......................

Correspondence to: Dr J T Macfarlane, Respiratory Infection Research Group, Respiratory Medicine, Nottingham City Hospital Nottingham NG5 1PB, UK; john.macfarlane@ tinyworld.co.uk

Revised version received 2 December 2002 Accepted for publication 13 December 2002

\begin{abstract}
Background: In the assessment of severity in community acquired pneumonia (CAP), the modified British Thoracic Society (mBTS) rule identifies patients with severe pneumonia but not patients who might be suitable for home management. A multicentre study was conducted to derive and validate a practical severity assessment model for stratifying adults hospitalised with CAP into different management groups.

Methods: Data from three prospective studies of CAP conducted in the UK, New Zealand, and the Netherlands were combined. A derivation cohort comprising $80 \%$ of the data was used to develop the model. Prognostic variables were identified using multiple logistic regression with 30 day mortality as the outcome measure. The final model was tested against the validation cohort.

Results: 1068 patients were studied (mean age 64 years, $51.5 \%$ male, 30 day mortality $9 \%$ ). Age $\geqslant 65$ years (OR $3.5,95 \% \mathrm{Cl} 1.6$ to 8.0 ) and albumin $<30 \mathrm{~g} / \mathrm{dl}(\mathrm{OR} 4.7,95 \% \mathrm{Cl} 2.5$ to 8.7 ) were independently associated with mortality over and above the $\mathrm{mBTS}$ rule (OR $5.2,95 \% \mathrm{Cl} 2.7$ to 10). A six point score, one point for each of Confusion, Urea $>7 \mathrm{mmol} / \mathrm{l}$, Respiratory rate $\geqslant 30 / \mathrm{min}$, low systolic $(<90 \mathrm{~mm} \mathrm{Hg}$ ) or diastolic ( $\leqslant 60 \mathrm{~mm} \mathrm{Hg}$ ) Blood pressure), age $\geqslant 65$ years (CURB-65 score) based on information available at initial hospital assessment, enabled patients to be stratified according to increasing risk of mortality: score $0,0.7 \%$; score $1,3.2 \%$; score $2,3 \%$; score $3,17 \%$; score 4 , $41.5 \%$ and score $5,57 \%$. The validation cohort confirmed a similar pattern.

Conclusions: A simple six point score based on confusion, urea, respiratory rate, blood pressure, and
\end{abstract} age can be used to stratify patients with CAP into different management groups. g $\mathrm{n}$ the assessment and management of community acquired pneumonia (CAP), disease severity assessment is crucial, guiding therapeutic options such as the need for hospital or intensive care (ICU) admission, suitability for discharge home, the extent of investigation, and choice and route of antimicrobial agent. ${ }^{2}$

The Pneumonia Severity Index (PSI) developed by Fine et al in the USA provides a means of stratifying groups of patients according to their risk of mortality and features in recently published North American guidelines. ${ }^{1-3}$ Unfortunately it is complicated to use, requiring computation of a score based on 20 variables, and hence may not be practical for routine application in busy hospital emergency departments or the primary care setting. In addition, it is best validated for assessing patients with a low mortality risk who may be suitable for home management rather than those with severe CAP at the time of hospital admission.

An alternative severity assessment tool proposed by the British Thoracic Society (BTS) and modified by Neill et al $(\text { mBTS })^{4}$ which relies on four easily measurable clinical features was developed mainly as a means of identifying patients with severe CAP at high risk of mortality. The presence of two or more of the following features-mental confusion, respiratory rate $\geqslant 30 / \mathrm{min}$, diastolic blood pressure $\leqslant 60 \mathrm{~mm} \mathrm{Hg}$, and blood urea $>7 \mathrm{mmol} / \mathrm{l}$-predicted mortality with an overall sensitivity and specificity of about $80 \% .^{5-7}$ However, this tool also has limitations; by stratifying patients into only two groups (severe or non-severe) it does not identify patients at low risk of mortality who might be suitable for early hospital discharge or home management. The aim of this study was to develop an assessment tool to enable stratifica- tion of patients presenting to hospital with CAP into mortality risk groups that might be suitable for different management options.

\section{METHODS \\ Study institutions and subjects}

Data from three large prospective studies of CAP were retrospectively combined into a single dataset. ${ }^{68}$ Adults admitted as medical emergencies with CAP to (1) Nottingham City Hospital (UK) over an 18 month period from 4 October 1998, (2) Christchurch and Waikato hospitals (New Zealand) over a 12 month period from 26 July 1999, and (3) Medical Centre Alkmaar (the Netherlands) over a 2 year period from December 1998 were eligible. All four participating study hospitals are teaching centres that admit unselected adults for acute medical care. All subjects gave written informed consent and ethical approval was obtained from local hospital ethics committees.

In all three studies CAP was defined as an acute respiratory tract illness associated with radiographic shadowing on an admission chest radiograph consistent with infection which was neither pre-existing nor of any other known cause. The following exclusion criteria applied: (1) pneumonia was (a) not the primary cause for hospital admission, (b) an expected terminal event, or (c) distal to bronchial obstruction; (2) patients with tuberculosis, bronchiectasis, solid organ and haematological malignancies or human immunodeficiency virus (HIV) infection; (3) patients who had been in hospital within the previous 14 days, were immunocompromised, or had previously been entered in the study; and (4) nursing home residents. In New Zealand and the Netherlands 
Table 1 Characteristics of study cohorts

\begin{tabular}{lllll}
\hline & $\begin{array}{l}\text { UK } \\
(\mathrm{n}=362)\end{array}$ & $\begin{array}{l}\mathrm{NZ} \\
(\mathrm{n}=452)\end{array}$ & $\begin{array}{l}\text { Netherlands } \\
(\mathrm{n}=254)\end{array}$ & $\begin{array}{l}\text { All } \\
(\mathrm{n}=1068)\end{array}$ \\
\hline Male (\%) & $181(50)$ & $231(51)$ & $138(54)$ & $550(51)$ \\
Mean age (years) & 64.9 & 63.5 & 64.1 & 64.1 \\
Age $\geqslant 65$ years (\%) & $210(58)$ & $256(57)$ & $155(61)$ & $621(58)$ \\
Age $\geqslant 75$ years (\%) & $140(39)$ & $159(35)$ & $92(36)$ & $391(37)$ \\
Prior antibiotics & $125(35)$ & $126(28)$ & $66(26)$ & $317(30)$ \\
Comorbid illnesses & & & & \\
Chronic lung disease & $128(35)$ & $121(27)$ & $126(50)$ & $375(35)$ \\
IHD/heart failure & $64(18)$ & $96(21)$ & $37(15)$ & $197(18)$ \\
CVD & $33(9)$ & $54(12)$ & $4(2)$ & $91(9)$ \\
Diabetes mellitus & $28(8)$ & $54(12)$ & $25(10)$ & $107(10)$ \\
Dementia & $16(4)$ & $24(5)$ & Not known & $11(1)$ \\
Chronic liver disease & $3(1)$ & $6(1)$ & $2(1)$ & $11)$ \\
Fine PSI risk class ${ }^{3}$ & & & & \\
I & $48(13)$ & $60(13)$ & $23(9)$ & $131(12)$ \\
II & $78(22)$ & $80(18)$ & $59(23)$ & $217(20)$ \\
III & $71(20)$ & $90(20)$ & $62(24)$ & $223(21)$ \\
IV & $123(34)$ & $145(32)$ & $88(35)$ & $356(33)$ \\
V & $42(12)$ & $77(17)$ & $22(9)$ & $141(13)$ \\
\hline IHD=ischaemic heart disease; CVD=cerebrovascular disease. & & \\
\hline
\end{tabular}

co-morbid illness was defined along the lines of Fine et al. ${ }^{3}$ Co-morbid illness was defined similarly in Nottingham as the presence of any of the following conditions for which the patient was under active medical supervision or was receiving treatment at the time of hospital admission: chronic lung disease, cardiac disease (ischaemic heart disease, cardiac failure, hypertension, atrial fibrillation), cerebrovascular disease (including previous transient ischaemic attacks), cognitive impairment, diabetes mellitus, chronic liver disease, chronic renal disease, and inflammatory rheumatological disorders (excluding osteoarthritis). Mental confusion was defined as a mental test score of 8 or less (UK, NZ) ${ }^{9}$ or disorientation in person, place or time (the Netherlands).

Patients were seen within 24 hours of admission by a study investigator and then regularly in hospital and after discharge until their clinical and radiological features had stabilised. The main outcome measure was 30 day mortality.

\section{Statistical analysis}

Data were analysed using SPSS Version 9.0 for Windows, Chicago, USA. The combined dataset was randomly divided into two to create a derivation cohort comprising $80 \%$ of the data and a validation cohort with the remaining $20 \%$. The derivation cohort was used to develop the severity assessment model. The size of the derivation cohort required was calculated to enable multiple logistic regression identifying seven independent prognostic features with no fewer than 10 outcome events per independent variable, thus avoiding the potential problem of overfitting of data. ${ }^{10}$ Based on an estimate of $80 \%$ sensitivity and specificity, this sample size would also allow the sensitivity and specificity of the mBTS rule to be determined with confidence intervals of $\pm 3 \%$ in the derivation cohort and $\pm 6 \%$ in the validation cohort.

Continuously distributed variables were re-categorised into binary factors using threshold values implicit in one or more of the existing severity prediction rules. Based on the mBTS assessment tool, a "CURB" severity score (Confusion, Urea $>7 \mathrm{mmol} / \mathrm{l}$, Respiratory rate $\geqslant 30 / \mathrm{min}$, and low Blood pressure (diastolic blood pressure (DBP) $\leqslant 60 \mathrm{~mm} \mathrm{Hg}$ or systolic blood pressure ( $\mathrm{SBP})<90 \mathrm{~mm} \mathrm{Hg}$ )) was calculated and one point given for each feature present (range $0-4$ points ). ${ }^{6}$ The association between the CURB score and 30 day mortality was examined and formed the basis for the development of a new severity assessment tool for stratifying patients into distinct risk groups.

Table 2 Association between selected clinical features and 30 day mortality on univariate analysis

\begin{tabular}{lllll}
\hline Clinical feature & $\mathrm{n}$ & OR & $95 \% \mathrm{Cl}$ & p value \\
\hline Age & & & & \\
$\quad<50$ years & 201 & Reference & \\
$50-64$ years & 145 & 0.9 & 0.3 to 3.3 & 0.9 \\
$65-74$ years & 179 & 3.0 & 1.1 to 7.8 & 0.03 \\
$75-84$ years & 190 & 5.4 & 2.2 to 13.4 & $<0.001$ \\
$\quad \geqslant 85$ years & 106 & 10 & 4.0 to 25.4 & $<0.001$ \\
Age $\geqslant 65$ years & 475 & 5.5 & 2.8 to 10.9 & $<0.001$ \\
Age $\geqslant 75$ years & 296 & 4.3 & 2.6 to 7 & $<0.001$ \\
Temperature $<37^{\circ} \mathrm{C}$ & 206 & 2.3 & 1.4 to 3.8 & $<0.001$ \\
Pulse $\geqslant 125 /$ min & 87 & 1.6 & 0.8 to 3.2 & 0.14 \\
Respiratory rate $\geqslant 30 /$ min & 277 & 1.7 & 1.07 to 2.8 & 0.02 \\
Mental confusion & 125 & 8.1 & 4.8 to 13.7 & $<0.001$ \\
Urea $>7$ mmol/I & 358 & 5.6 & 3.1 to 10 & $<0.001$ \\
Albumin $<30 \mathrm{~g} / \mathrm{dl}$ & 124 & 4.9 & 2.8 to 8.4 & $<0.001$ \\
PaO $2<8 \mathrm{kPa}$ & 267 & 1.8 & 1.07 to 3.0 & 0.03 \\
Chest radiograph: multilobar & 243 & 1.2 & 0.7 to 2.0 & 0.4 \\
Chest radiograph: effusion & 116 & 1.8 & 1.03 to 3.3 & 0.04 \\
Low $\mathrm{BP}$ (SBP $<90$ or DBP $\leqslant 60 \mathrm{~mm} \mathrm{Hg)}$ & 199 & 2.4 & 1.4 to 3.8 & $<0.001$ \\
\hline
\end{tabular}


Table 3 Multivariate analysis using CURB as a binary variable $(2$ or more features $=$ severe) to identify other factors that are independently associated with mortality $(n=637)$

\begin{tabular}{llll}
\hline Clinical feature & OR & $95 \% \mathrm{Cl}$ & $\mathrm{p}$ value \\
\hline Albumin $<30 \mathrm{~g} / \mathrm{dl}$ & 4.7 & 2.5 to 8.7 & $<0.001$ \\
Age $\geqslant 65$ years & 3.5 & 1.6 to 8.0 & 0.003 \\
Temperature $<37^{\circ} \mathrm{C}$ & 1.9 & 1.01 to 3.6 & 0.047 \\
CURB score $\geqslant 2$ (severe CAP) & 5.2 & 2.7 to 10.3 & $<0.001$ \\
\hline
\end{tabular}

The univariate association between 30 day mortality and each potential predictor variable, including the CURB score and each of the components of the CURB score, was analysed using a $\chi^{2}$ test. To avoid spurious associations arising from multiple statistical tests, 12 predictor variables selected from the current literature as most consistently important in predicting prognosis in CAP were examined. . $^{3-511-19}$ This established that each of the components of the CURB score is a predictor of mortality. Independent predictors over and above the CURB score were identified by entering the CURB score as a single variable plus each of the other potential predictors into a backward logistic regression. The CURB score was categorised as $<2$ or $\geqslant 2$ in this model, a score of $\geqslant 2$ being taken to identify patients with severe CAP. Following backward regression, each of the excluded variables was entered back into the suggested model to ensure they had no effect on the final model.

A clinical prediction rule based on the CURB score and the newly identified independent prognostic features was subsequently derived. In order to ensure that the final prediction rule remained simple to use and practical, prognostic features not usually available at the time of initial assessment on hospital admission were excluded from the model. All results were tested against the validation cohort. The results are expressed as odds ratios (OR) and p values with 95\% confidence intervals (CI) and using receiver operating curves (ROC) to plot sensitivity against specificity.
Table 5 Test characteristics of rules with different prediction scores for 30 day mortality in the derivation and validation sets of patients hospitalised with CAP

\begin{tabular}{|c|c|c|c|c|c|}
\hline Rule & $\begin{array}{l}\text { No of } \\
\text { features }\end{array}$ & $\begin{array}{l}\text { Sensitivity } \\
(\%)\end{array}$ & $\begin{array}{l}\text { Specificity } \\
(\%)\end{array}$ & PPV (\%) & NPV (\%) \\
\hline \multicolumn{6}{|c|}{ Derivation set $(n=718)$} \\
\hline \multirow[t]{5}{*}{ CURB } & $\geqslant 0$ & 100.0 & 0.0 & 9.6 & NA \\
\hline & $\geqslant 1$ & 95.7 & 33.0 & 13.2 & 98.6 \\
\hline & $\geqslant 2$ & 75.4 & 68.9 & 20.5 & 96.3 \\
\hline & $\geqslant 3$ & 42.0 & 90.3 & 31.5 & 93.6 \\
\hline & $\geqslant 4$ & 1.4 & 99.1 & 14.3 & 90.4 \\
\hline \multirow[t]{6}{*}{ CURB-65 } & $\geqslant 0$ & 100.0 & 0.0 & 9.6 & NA \\
\hline & $\geqslant 1$ & 98.6 & 21.0 & 11.7 & 99.3 \\
\hline & $\geqslant 2$ & 92.8 & 49.2 & 16.2 & 98.5 \\
\hline & $\geqslant 3$ & 68.1 & 74.9 & 22.4 & 95.7 \\
\hline & $\geqslant 4$ & 39.1 & 93.1 & 37.5 & 93.5 \\
\hline & $\geqslant 5$ & 1.4 & 99.1 & 14.3 & 90.4 \\
\hline \multirow[t]{5}{*}{ CRB-65 } & $\geqslant 0$ & 100.0 & 0.0 & 9.6 & NA \\
\hline & $\geqslant 1$ & 97.1 & 25.4 & 12.2 & 98.8 \\
\hline & $\geqslant 2$ & 76.8 & 64.3 & 18.6 & 96.3 \\
\hline & $\geqslant 3$ & 43.5 & 89.8 & 31.3 & 93.7 \\
\hline & $\geqslant 4$ & 2.9 & 98.6 & 18.2 & 90.5 \\
\hline \multicolumn{6}{|c|}{ Validation set $(n=214)$} \\
\hline \multirow[t]{5}{*}{ CURB } & $\geqslant 0$ & 100.0 & 0.0 & 9.3 & NA \\
\hline & $\geqslant 1$ & 100.0 & 28.4 & 12.6 & 100.0 \\
\hline & $\geqslant 2$ & 75.0 & 70.1 & 20.5 & 96.5 \\
\hline & $\geqslant 3$ & 35.0 & 89.7 & 25.9 & 93.0 \\
\hline & $\geqslant 4$ & 5.0 & 98.5 & 25.0 & 91.0 \\
\hline \multirow[t]{6}{*}{ CURB-65 } & $\geqslant 0$ & 100.0 & 0.0 & 9.3 & NA \\
\hline & $\geqslant 1$ & 100.0 & 18.6 & 11.2 & 100.0 \\
\hline & $\geqslant 2$ & 100.0 & 46.4 & 16.1 & 100.0 \\
\hline & $\geqslant 3$ & 75.0 & 74.7 & 23.4 & 96.7 \\
\hline & $\geqslant 4$ & 30.0 & 91.8 & 27.3 & 92.7 \\
\hline & $\geqslant 5$ & 5.0 & 99.0 & 33.3 & 91.0 \\
\hline \multirow[t]{5}{*}{ CRB-65 } & $\geqslant 0$ & 100.0 & 0.0 & 9.3 & NA \\
\hline & $\geqslant 1$ & 100.0 & 23.2 & 11.8 & 100.0 \\
\hline & $\geqslant 2$ & 80.0 & 61.3 & 17.6 & 96.7 \\
\hline & $\geqslant 3$ & 45.0 & 89.7 & 31.0 & 94.1 \\
\hline & $\geqslant 4$ & 5.0 & 99.0 & 33.3 & 91.0 \\
\hline
\end{tabular}

PPV=positive predictive value; $N P V=$ negative predictive value.

Table 4 Relationship between number of core adverse prognostic features, age $\geqslant 65$ years, and risk of mortality

\begin{tabular}{|c|c|c|c|c|c|}
\hline \multirow[b]{2}{*}{ Features } & \multirow{2}{*}{$\begin{array}{l}\text { No. } \\
\text { present }\end{array}$} & \multicolumn{2}{|c|}{ Derivation cohort $(n=718)$} & \multicolumn{2}{|c|}{ Validation cohort $(n=214)$} \\
\hline & & Total & Died (\%) & Total & Died (\%) \\
\hline \multirow[t]{5}{*}{ CURB } & 0 & 217 & $3(1.4)$ & 55 & 0 \\
\hline & 1 & 247 & $14(5.4)$ & 86 & $5(5.8)$ \\
\hline & 2 & 162 & $23(14.2)$ & 46 & $8(17.4)$ \\
\hline & 3 & 85 & 28 (32.9) & 23 & $6(26)$ \\
\hline & 4 & 7 & $1(14.3)$ & 4 & $1(25)$ \\
\hline \multirow[t]{6}{*}{ CURB-65 } & 0 & 137 & $1(0.7)$ & 36 & 0 \\
\hline & 1 & 187 & $4(2.1)$ & 54 & 0 \\
\hline & 2 & 184 & $17(9.2)$ & 60 & $5(8.3)$ \\
\hline & 3 & 138 & 20 (14.5) & 42 & 9 (21.4) \\
\hline & 4 & 65 & $26(40)$ & 19 & $5(26.3)$ \\
\hline & 5 & 7 & $1(14)$ & 3 & $1(33.3)$ \\
\hline \multirow[t]{5}{*}{ CRB-65 } & 0 & 167 & $2(1.2)$ & 45 & 0 \\
\hline & 1 & 266 & $14(5.3)$ & 78 & $4(5.1)$ \\
\hline & 2 & 189 & 23 (12.2) & 62 & 7 (11.3) \\
\hline & 3 & 85 & 28 (32.9) & 26 & $8(30.8)$ \\
\hline & 4 & 11 & $2(18.2)$ & 3 & $1(33.3)$ \\
\hline \multicolumn{6}{|c|}{$\begin{array}{l}\text { CURB }=\text { Confusion, Urea }>7 \mathrm{mmol} / \mathrm{I} \text {, Respiratory rate } \geqslant 30 / \mathrm{min} \text {, low Blood pressure (systolic }<90 \mathrm{~mm} \mathrm{Hg} \text { or } \\
\text { diastolic } \leqslant 60 \mathrm{~mm} \mathrm{Hg} \text { ). } \\
\text { CRB-65 does not include urea and uses only clinical parameters available for patient assessment in the } \\
\text { community. }\end{array}$} \\
\hline
\end{tabular}




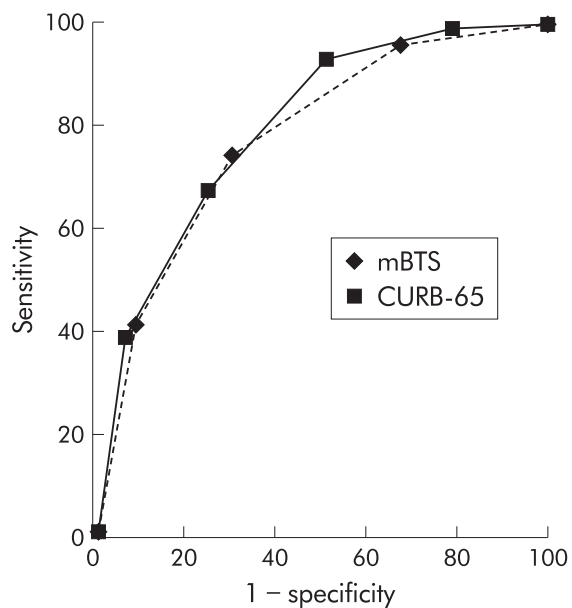

Figure 1 Receiver operating curves for modified BTS (mBTS) rule and CURB-65 score.

\section{RESULTS}

One thousand and sixty eight patients, 550 (51.5\%) male, were studied. The mean (median, range) age of the patients was $64.1(69,17-100)$ years and $391(37 \%)$ were aged 75 years and above. Baseline characteristics of patients from the three study centres were very similar (table 1).

All patients were treated with empirical antimicrobial agents according to local hospital guidelines. This usually comprised a $\beta$-lactamase stable $\beta$-lactam in combination with a macrolide. Dutch patients were randomised within 2 hours of admission to receive either empirical treatment according to the ATS guidelines or pathogen directed treatment based on the results of rapid microbiological tests (Gram stain or antigen detection). ${ }^{20}$ The intravenous route was used in 920 patients $(86 \%) ; 55(5 \%)$ were admitted to the ICU and $44(4 \%)$ required mechanical ventilation. The 30 day mortality was $9 \%$.

\section{Associations with $\mathbf{3 0}$ day mortality}

There were 821 patients in the derivation cohort. Of the 29 patients with an SBP $<90 \mathrm{~mm} \mathrm{Hg}, 28(97 \%)$ had a DBP of $60 \mathrm{~mm} \mathrm{Hg}$ or less. These two features were therefore combined as the presence of one or both and analysed as a single variable (low BP). Of the 11 features examined for an association with mortality on univariate analysis, all except multilobar shadowing on chest radiography and a pulse rate of $\geqslant 125 /$ min were found to be significant (table 2). Increasing age cohorts were associated with increasing mortality.

Serum albumin $<30 \mathrm{~g} / \mathrm{dl}$ and age $\geqslant 65$ years were both independently associated with 30 day mortality after adjusting for CURB score (table 3 ). Although an association between temperature $<37^{\circ} \mathrm{C}$ and mortality was found on multivariate analysis, this only just achieved statistical significance (OR $1.9,95 \%$ CI 1.01 to 3.6, p<0.047). Entering each of the other variables in turn back into the resulting model did not alter the results.

\section{Development of practical clinical prediction rule}

The sensitivity and specificity of the mBTS rule-that is, a CURB score of 2 or more-in the derivation cohort was $75 \%$ (95\% CI 72 to 78 ) and $69 \%$ (95\% CI 66 to 72 ), respectively. Corresponding values in the validation cohort were $74 \%$ (95\% CI 68 to 80 ) and $73 \%$ (95\% CI 67 to 79$)$.

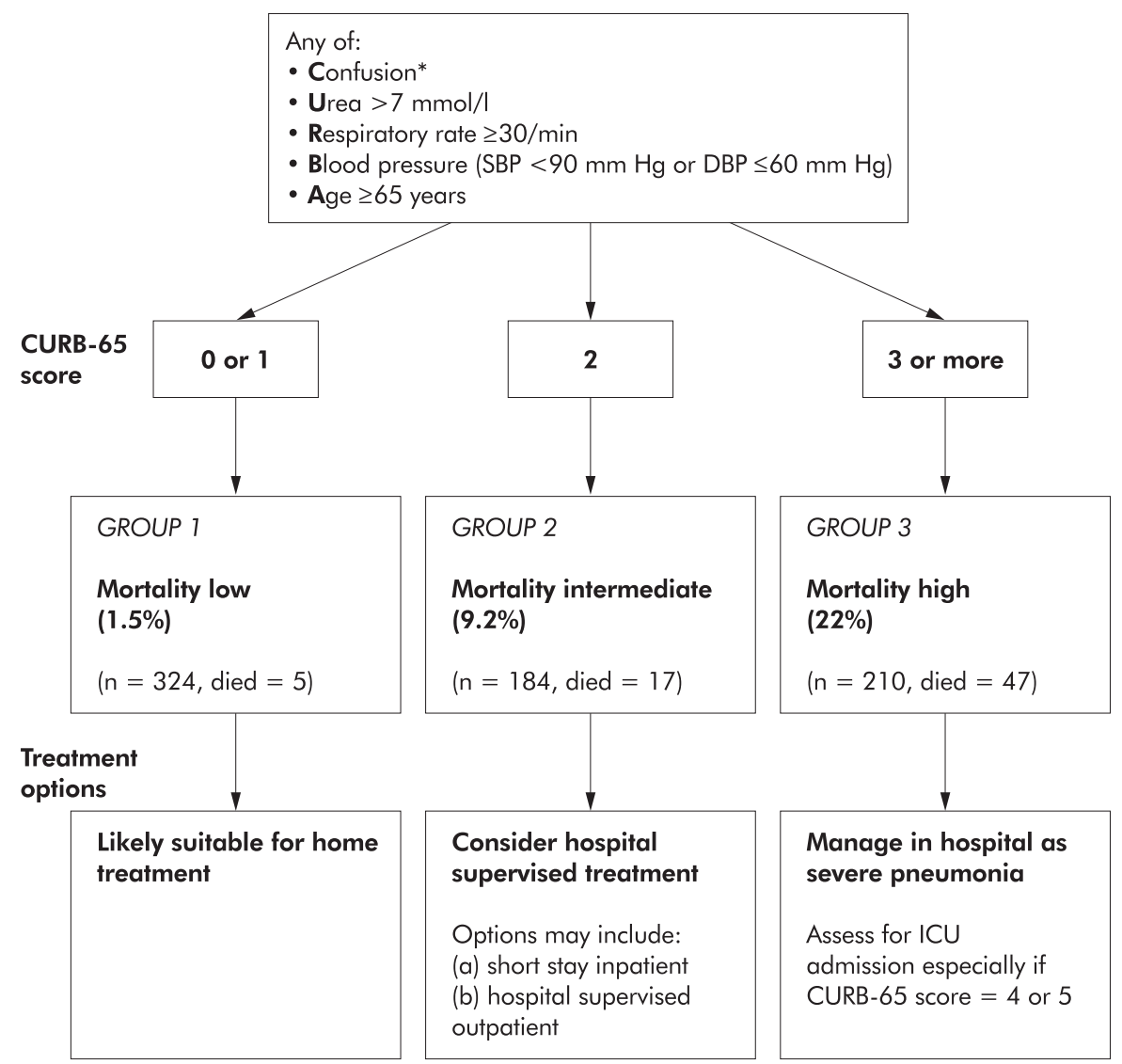

*defined as a Mental Test Score of 8 or less, or new disorientation in person, place or time

Figure 2 Severity assessment in a hospital setting: the CURB-65 score. One step strategy for stratifying patients with CAP into risk groups according to risk of mortality at 30 days when the results of blood urea are available. 


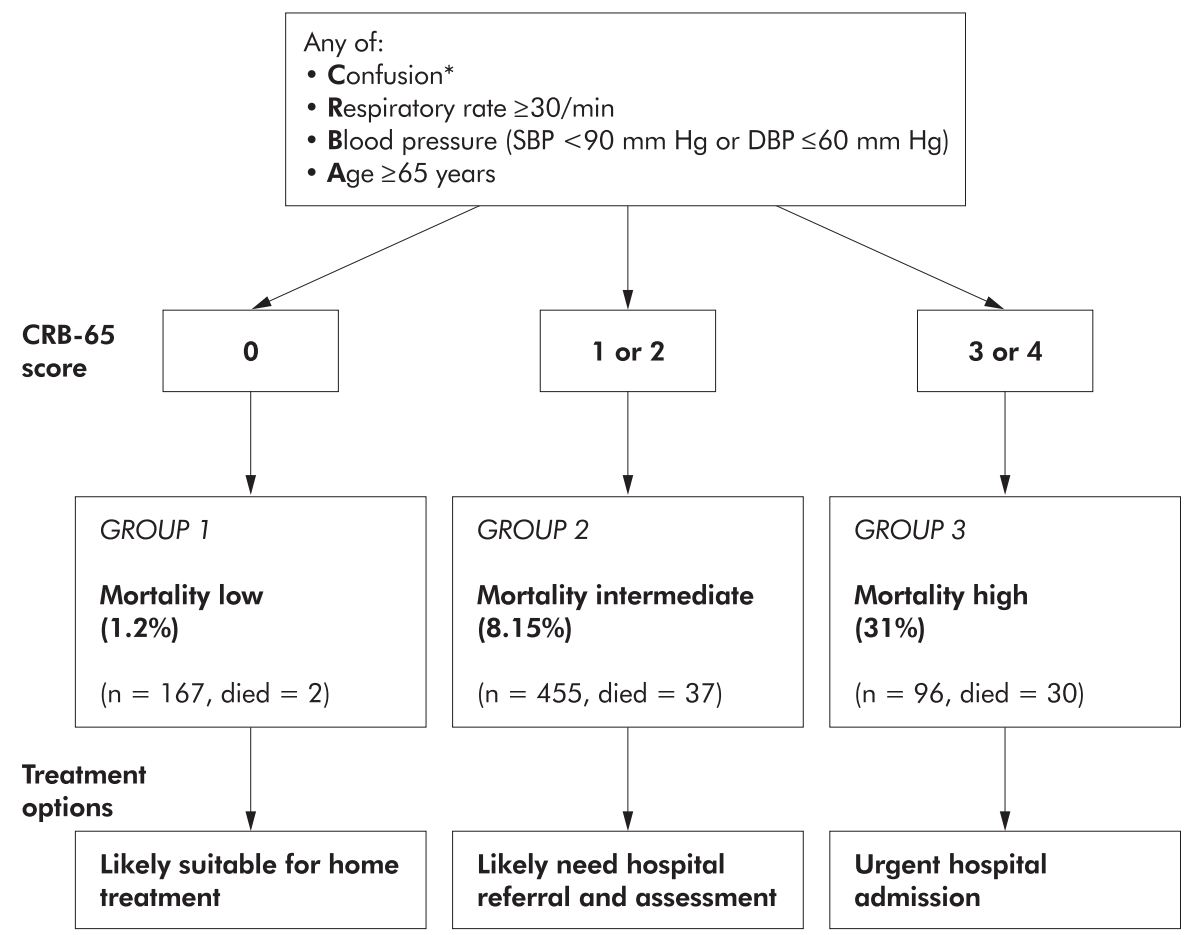

*defined as a Mental Test Score of 8 or less, or new disorientation in person, place or time

Figure 3 Clinical severity assessment in the community setting: the CRB-65 score. Strategy for stratifying patients with CAP into risk groups in the community using only clinical observations (when blood urea results not available).

Based on the results of the multivariate analysis, age $\geqslant 65$ years was added as another adverse prognostic feature to the CURB score resulting in a six point score (CURB-65, range 0-5) which allowed patients to be stratified according to increasing risk of mortality ranging from $0.7 \%$ (score 0 ) to $40 \%$ (score 4 ; table 4 ) The numbers with a score of 5 (highest) were small; of the seven patients, only one (14\%) died. However, three $(43 \%)$ others required mechanical ventilation in an intensive care setting and survived. A further model based only on clinical features available from a clinical assessment without laboratory results (confusion, respiratory rate, blood pressure, and age; CRB-65 score) was also tested and found to correlate well with risk of mortality and need for mechanical ventilation. These models performed equally well when applied to the validation cohort (table 4). The sensitivities, specificities, and predictive values of the different rules for predicting 30 day mortality are given in table 5 and fig 1 .

\section{DISCUSSION}

This is the largest cohort study of severity assessment in CAP conducted outside the USA. The strength of this study lies in the large sample size, the prospective and systematic collection of relevant clinical information, the focusing of statistical tests of association on selected clinical features based on the current evidence base (thus avoiding spurious associations), and the inclusion of unselected adults of all ages. Furthermore, the study cohort comprised patients admitted as unselected emergencies into public (that is, government funded) hospitals in three countries with similar primary and secondary healthcare systems. This is supported by the observation that direct GP referrals comprised $62 \%$ and $70 \%$ of the admissions in the NZ and UK cohorts, respectively (the source of referral was not recorded in the Netherlands but it is estimated that $\sim 60 \%$ of the admissions were referred by a GP). Also, emergency medical admissions to private healthcare facilities rarely happen in these countries. This should allow the results to be generalised to other countries which share such healthcare systems, which differ from those in the USA.
Although the profiles of the three cohorts are very similar (table 1), there may be other potential differences between the cohorts which may not be obvious. This represents a limitation of the study.

The importance of mental confusion, low blood pressure, raised respiratory rate, and raised urea as "core" adverse prognostic features in patients admitted to hospital with CAP is underlined. This study confirmed our previous finding in the UK subset of patients that a simple severity scoring system based on these four adverse prognostic features (CURB score) correlates well with mortality. ${ }^{6}$

In the development of a clinical prediction rule suitable for use in busy casualty departments or admission units, we sought to include clinical features of prognostic importance which were easily measurable at the time of initial assessment. Thus, although both age $\geqslant 65$ years and a low serum albumin were identified as independent prognostic variables in addition to the CURB score, the latter was not included in the final model as it is not a routinely available test in many hospitals, particularly out of hours. In contrast, age is easy to determine and has been consistently found to be very strongly associated with prognosis in most studies of severity assessment in adults with CAP. ${ }^{21}$ Indeed, the determination of the score in the PSI developed by Fine et al is heavily influenced by age.

The overall sensitivity and specificity of the CURB-65 score is similar to the mBTS severity assessment tool as seen in the receiver operating curves (ROC) in fig 1 . The advantage of the CURB-65 score is that it provides a bigger range of sensitivities for specificity, thus enabling patients to be stratified as possibly suitable for three different management options. Patients with scores 0 and 1 are at low risk of mortality $(<2 \%)$ and might be suitable for management as hospital outpatients or by their general practitioner (fig 2). Patients with a score of 2 are at intermediate risk of mortality (9\%) and should be considered for hospital supervised treatment. Patients with a score of $>2$ are at high risk of mortality $(>19 \%)$ and correspond to those patients who meet the mBTS criteria for 
severe CAP. They should be treated in hospital. Initial care in an intensive care or high dependency unit may be appropriate in those with the highest scores.

These three groupings are similar in terms of risk of mortality to the treatment groups identified by the PSI when applied to this study cohort (risk class I-III, mortality $<3.2 \%$; risk class IV, mortality 12\%; and risk class V, mortality $32 \%$ ). However, as discussed in the Canadian and American Thoracic Society (ATS) guidelines, the PSI has practical limitations related to its complexity which may restrict its widespread adoption. Indeed, the ATS guidelines do not offer any algorithm for the clinical assessment of disease severity. ${ }^{22}$ The advantage of the CURB-65 severity assessment tool is that it is simple to use, relying on only five (rather than 20) easily measurable features, with all but urea being clinical observations which could be made by healthcare workers in primary and secondary care. It may also be useful in the community for general practitioners when deciding on the need for hospital referral for patients with CAP, even if the blood urea is unavailable (fig 3). In all instances overall clinical judgement is crucial. Social factors and patients' wishes will also influence where to manage a patient. Whether the proposed CURB-65 score can be applied in conjunction with different management strategies to improve clinical outcomes and health service utilisation requires further study.

This study offers a simple clinical prediction rule based on the five clinical features of age, confusion, urea, respiratory rate, and blood pressure (CURB-65 score) as a practical means of stratifying patients with CAP into low, intermediate, and high mortality risk groups. The size of the dataset and the consistency of the findings in derivation and validation cohorts suggest that this rule could be applied with some confidence in practice while undergoing further prospective evaluations.

\section{ACKNOWLEDGEMENTS}

The authors acknowledge the following for their help with the study: Associate Professor Stephen Chambers, infectious diseases physician; Dr Chris Frampton, biostatistician; Dr Rodger Jackson, radiologist; Dr David Murdoch, clinical microbiologist; Dr Lance Jennings, virologist; and Dr Jenny McWha, research nurse (all in New Zealand); all the physicians at Nottingham City Hospital who allowed the study of their patients; Dr Don Rose, radiologist; and Melanie Caine, research nurse.

\section{Authors' affiliations}

W S Lim, J T Macfarlane, Respiratory Infection Research Group, Respiratory Medicine, Nottingham City Hospital, Nottingham NG5 IPB, UK

M M van der Eerden, W G Boersma, Medical Centre Alkmaar, PO Box 501, 1800 AM Alkmaar, The Netherlands

R Laing, G I Town, Christchurch School of Medicine and Health Sciences, University of Otago, Christchurch Hospital, Christchurch, New Zealand

N Karalus, Waikato Respiratory Department, Health Waikato, Hamilton, New Zealand

S A Lewis, Division of Respiratory Medicine, Nottingham City Hospital, Nottingham NG5 1PB, UK

Funding: Nottingham: local trust fund and educational grant from
Hoechst Marion Roussel; New Zealand: Health Research Council of New Zealand; The Netherlands: partial funding by grants from Astra Zeneca BV Netherlands and Pfizer BV Netherlands.

\section{REFERENCES}

1 Bartlett JG, Dowell SF, Mandell LA, et al. Practice guidelines for the management of community-acquired pneumonia in adults. Infectious Diseases Society of America. Clin Infect Dis 2000;31:347-82.

2 Mandell LA, Marrie TJ, Grossman RF, et al. Canadian guidelines for the initial management of community-acquired pneumonia: an evidence-based update by the Canadian Infectious Diseases Society and the Canadian Thoracic Society. The Canadian Community- Acquired Pneumonia Working Group. Clin Infect Dis 2000;31:383-421.

3 Fine MJ, Auble TE, Yealy DM, et al. A prediction rule to identify low-risk patients with community- acquired pneumonia. N Engl J Med 1997:336:243-50.

4 Neill AM, Martin IR, Weir R, et al. Community acquired pneumonia: aetiology and usefulness of severity criteria on admission. Thorax 1996;51:1010-6.

5 British Thoracic Society and Public Health Laboratory Service. Community-acquired pneumonia in adults in British hospitals in 1982-1983: a survey of aetiology, mortality, prognostic factors and outcome. Q J Med 1987;62:195-220.

6 Lim WS, Macfarlane JT, Boswell TC, et al. Study of community acquired pneumonia aetiology (SCAPA) in adults admitted to hospital: implications for management guidelines. Thorax 2001;56:296-301.

7 Lim WS, Lewis S, Macfarlane JT. Severity prediction rules in community acquired pneumonia: a validation study. Thorax 2000;55:219-23.

8 Van der Eerden MM, de Graaff CS, Bronsveld W, et al. Validation of prediction rule to identify low risk patients with community-acquired pneumonia (CAP). Am J Respir Crit Care Med 2001;163:A806.

9 Qureshi KN, Hodkinson HM. Evaluation of a ten-question mental test in the institutionalized elderly. Age Ageing 1974;3:152-7.

10 Concato J, Feinstein AR. Monte Carlo methods in clinical research: applications in multivariable analysis. J Invest Med 1997:45:394-400.

11 Riquelme R, Torres A, El-Ebiary $M$, et al. Community-acquired pneumonia in the elderly: a multivariate analysis of risk and prognostic factors. Am J Respir Crit Care Med 1996;154:1450-5.

12 Janssens JP, Gauthey L, Herrmann F, et al. Community-acquired pneumonia in older patients. J Am Geriatr Soc 1996;44:539-44.

13 Marrie TJ, Durant H, Yates L. Community-acquired pneumonia requiring hospitalization: 5-year prospective study. Rev Infect Dis 1989;11:586-99.

14 Ortqvist A, Hedlund J, Grillner L, et al. Aetiology, outcome and prognostic factors in community-acquired pneumonia requiring hospitalization. Eur Respir J 1990;3:1105-13.

15 Farr BM, Sloman A, Fisch M. Predicting death in patients hospitalized for community-acquired pneumonia. Ann Intern Med 1991; 1 15:428-36.

16 Fine MJ, Smith MA, Carson CA, et al. Prognosis and outcomes of patients with community-acquired pneumonia. A meta-analysis. JAMA 1996;275: 134-41

17 Ewig S, Baver T, Hasper E, et al. Prognostic analysis and predictive rule for outcome of hospital- treated community-acquired pneumonia. Eur Respir J 1995; 8:392-7.

18 Hasley PB, Albaum MN, Li YH, et al. Do pulmonary radiographic findings at presentation predict mortality in patients with community-acquired pneumonia? Arch Intern Med 1996;156:2206-12.

19 Lim WS, Macfarlane JT. Defining prognostic factors in the elderly with community acquired pneumonia: a case controlled study of patients aged 75 years and above. Eur Respir J 2001;17:200-5.

20 Van Kasteren ME, Wijnands WJ, Stobberingh EE, et al. Optimaliseren van het antibioticabeleid in Nederland. SWAB-richtlijnen voor antimicorbiële therapie bii thuis opgelopen pneumonie en bii nosocomiale pneumonie. Ned Tiidschr Geneeskd 1998:142:952-6.

21 Fine MJ, Singer DE, Hanusa BH, et al. Validation of a pneumonia prognostic index using the MedisGroups Comparative Hospital Database. Am J Med 1993;94:153-9.

22 Niederman MS, Mandell LA, Anzueto A, et al. Guidelines for the management of adults with community-acquired pneumonia. Diagnosis, assessment of severity, antimicrobial therapy, and prevention. Am J Respir Crit Care Med 2001;163:1730-54. 